\title{
LA REFORMA CONSTITUCIONAL Y LA GOBERNANZA ECONÓMICA DE LA UNIÓN EUROPEA
}

\author{
ANTONIO BAR CENDÓN \\ Catedrático de Derecho Constitucional \\ Catedrático Jean Monnet de Derecho Constitucional de la UE \\ Universidad de Valencia
}

\author{
SUMARIO.- \\ I. Introducción \\ II. Las reformas constitucionales de los Estados \\ III. Las reformas de la gobernanza económica de la \\ Unión Europea \\ IV. El Pacto para el Crecimiento y el Empleo \\ V. ¿Hacia una auténtica Unión Económica y Mo- \\ netaria?
}

\section{INTRODUCCIÓN}

En septiembre de 2011, el Boletín Oficial del Estado publicaba el texto de la segunda reforma de la Constitución Española de 1978. ${ }^{1}$ A diferencia de la anterior (agosto de 1992), ${ }^{2}$ la reforma de 2011 no suscitó un consenso muy amplio. Por el contrario, la reforma de 2011 se produjo en circunstancias excepcionales y vino acompañada por un duro debate político y fuertes críticas en algunos sectores de la doctrina constitucionalista. De hecho, sólo el partido entonces en el Gobierno —el PSOE_ y el principal grupo de la oposición — el PP — se manifestaron claramente favorables a la reforma desde el inicio del proceso y pactaron entre ellos, no sólo el contenido material del nuevo Art. 135

1 Reforma del artículo 135 de la Constitución Española, de 27 de septiembre de 2011 (BOE n 233, 27.9.2011).

2 Reforma del artículo 13, apartado 2, de la Constitución Española, de 27 de agosto de 1992 (BOE n 207, 28.8.1992). 
de la Constitución, sino también el procedimiento parlamentario a seguir, ${ }^{3}$ y, desde luego, la decisión misma de reformar el texto fundamental — su oportunidad- y el momento para hacerlo.

Pero, en realidad, la reforma constitucional de 2011 no fue verdaderamente el resultado de una decisión autónoma, racionalmente adoptada por el Gobierno y el principal grupo de la oposición, sino, más bien al contrario, el resultado necesario de las condiciones económicas y financieras del momento y, desde luego, de las exigencias provenientes de Europa, que demandaban — y demandan aún hoy — un equilibrio financiero y presupuestario que España no alcanzaba entonces y que, paradójicamente, está aún más lejos de alcanzar hoy, un año después de aquella reforma constitucional y de otras reformas realizadas a través de la legislación ordinaria. ${ }^{4}$ Y utilizo aquí el término Europa, y no Unión Europea, de una manera intencionada, por cuanto buena parte de esas exigencias no han sido formuladas, en términos propios, por órganos de gobierno de la UE —el Consejo, la Comisión, el Banco Central Europeo, el Eurogrupo-, ni tampoco lo han sido a través de normas jurídicas propias del Derecho de la Unión, sino que se ha tratado, más bien, de decisiones y pactos acordados por Estados de la Unión, y de decisiones o recomendaciones de tipo político. Y, en fin, se ha tratado — se trata aún- de actos o decisiones en cuya adopción España ha sido también un sujeto codecisor importante y, por lo tanto, no la inocente víctima de una imposición foránea de algo que no era querido o solicitado, como con harta frecuencia se suele decir en el discurso político de los gobernantes e, incluso, en los medios de comunicación especializados.

Por otra parte, la reforma constitucional de 2011 no se produjo de una manera aislada, sino en el medio de un contexto de reforma general de las instituciones y de los modos de gobernar la economía y las finanzas públicas — la gobernanza económica-, tanto en el seno de la misma UE, como en el seno de una buena parte de sus Estados miembros. Estos cambios vinieron inicialmente determinados por la grave crisis financiera que afectó a Europa a partir de la segunda mitad del año 2008, y que se convirtió en especialmente dramática en los años 2009 y 2010, especialmente en Estados como Grecia, Irlanda y Portugal, que tuvieron que ser ayudados económicamente por la UE para evitar su quiebra total. El problema se hizo especialmente grave cuando, en enero de 2010, se descubrió no sólo los elevadísimos niveles de deuda y de déficit públicos de Grecia, sino que este país había venido falseando los informes que presentaba a la UE, en virtud de las previsiones de los Tratados con respecto a la coordinación de las políticas económicas y el control del déficit público excesivo. ${ }^{5}$ El caso griego venía a poner en

3 Se decidió que la reforma se realizase por el procedimiento de tramitación directa y en lectura única de la proposición de reforma constitucional correspondiente, en virtud de lo dispuesto en el Art. 150 del Reglamento del Congreso de los Diputados. La proposición fue presentada por los grupos parlamentarios Socialista y Popular en el Congreso de los Diputados (BOCG-Congreso de los Diputados, serie B, n 329-1, 26.8.2011, pág. 2).

4 La prima de riesgo de la deuda pública española era en septiembre de 2011 de 400 puntos básicos. En el momento de redactar estas líneas, en junio de 2012, ha llegado a alcanzar la cifra de 589 puntos básicos, con un interés nominal del bono español a diez años del 7,29\%.

5 Vid. Arts. 99 y 104 del TCE (actuales Arts. 121 y 126 del TFUE), Protocolo sobre el procedimiento aplicable en caso de déficit excesivo (actual Protocolo $n^{\circ}$ 12), y actual Declaración ( $n^{\circ}$ 30) relativa al artículo 126 del Tratado de Funcionamiento de la Unión Europea. 
cuestión la solvencia y credibilidad del euro como moneda, dado que, si Grecia había sido aceptada y mantenida en la eurozona con unos datos macroeconómicos falsos ¿qué credibilidad ofrecía a los mercados de capitales el euro mismo, como moneda, y el conjunto de la eurozona? A ello, claro es, se añadía el problema que planteaban las elevadas deudas y déficits públicos de Irlanda y de Portugal, los cuales, si bien de origen y condiciones diferentes, venían a añadir combustible a una hoguera que amenazaba con quemar completamente una dimensión tan relevante del proceso de integración de Europa como lo era — lo es - la unión económica y monetaria.

La Unión Europea, como tal unión, y sus Estados miembros de manera particular, en su propio terreno, necesitaban reaccionar de manera inmediata y contundente, poniendo cortafuegos que evitasen la extensión del incendio y adoptando medidas urgentes y específicas que tratasen de sofocarlo en cada uno de sus focos. Es en este sentido y en este contexto como se van a producir las medidas jurídicas, políticas y estratégicas de las que se ocupa este trabajo. Medidas adoptadas por los Estados miembros, de manera particular, y medidas adoptadas también por la UE, de manera general.

En las líneas que siguen, pues, en primer lugar, se analizan las medidas adoptadas por los Estados, concentrando el estudio en los proyectos de reforma constitucional formulados y su conclusión en la práctica; y, en segundo lugar, se analizan las medidas adoptadas por la UE, dentro del marco del ordenamiento jurídico de la Unión, y por los Estados miembros, de manera conjunta, pero al margen del ordenamiento jurídico de la UE.

\section{LAS REFORMAS CONSTITUCIONALES DE LOS ESTADOS}

Una de las líneas más contundentes y determinantes de actuación frente a la crisis financiera es la reforma constitucional. Se trata de incluir en los textos constitucionales la llamada «regla de oro» ( «golden rule») de la estabilidad financiera; es decir, que las finanzas públicas — que las previsiones presupuestarias de ingresos y de gastos- se encuentren siempre en situación de equilibrio, o de superávit.

Esta práctica de incluir la «regla de oro» de la estabilidad financiera en los textos constitucionales se inició en la segunda mitad del siglo pasado en los Estados Unidos de Norteamérica y, ya en los años 80, la práctica totalidad de los Estados federados disponían en sus constituciones de previsiones de este carácter —aunque relativamente diferentes en su formulación_-, además, claro es, del desarrollo legislativo correspondiente. ${ }^{6}$

En Europa, fue la propia Unión Europea la que, en su mismo tratado fundacional, fijó la regla de que «Los Estados miembros evitarán déficits públicos excesivos», atribuyendo a la Comisión Europea el papel de supervisar la evolución de la situación presupuestaria y el

6 De los cincuenta Estados miembros de la Federación, sólo nueve carecen de una previsión constitucional a este respecto (Alaska, Arkansas, Indiana, Mississippi, New Hampshire, Vermont, Virginia, Washington, Wyoming), si bien todos ellos, excepto cuatro (Indiana, Vermont, Virginia, Wyoming), disponen de previsiones de este carácter en la legislación ordinaria del Estado. Vid. HOWARD, M, State Balanced Budget Requirements: Provisions and Practice (Washington, D.C., National Association of State Budget Officers, June 1992); National Conference of State Legislatures, Fundamentals of Sound State Budgeting Practices (Washington, NCSL, June 1995); National Conference of State Legislatures, Fiscal Brief: State Balanced Budget Provisions (Washington, NCSL, October 2010). 
nivel de endeudamiento público de los Estados miembros, al mismo tiempo que — como veremos de nuevo más adelante- fijaba los criterios con respecto a los cuales se medirían los conceptos de deuda pública y de déficit público excesivos (Art. $104 \mathrm{C}$ del Tratado de la Comunidad Europea, reformado por el Tratado de Maastricht, de 7.2.1992)

El primer Estado europeo en introducir en su Constitución la regla de la estabilidad financiera o presupuestaria, sin embargo, no sería un Estado miembro de la UE y lo haría, además, casi diez años después: fue Suiza, en el año 2001. El caso suizo es peculiar también por cuanto se trata del único caso en el que esta previsión fue aprobada en referéndum por los ciudadanos de aquel país, tras el correspondiente debate parlamentario. ${ }^{7}$ Así, el nuevo Art. 126 ( «Gestion des finances») de la Constitución suiza establece, en sustancia, lo siguiente: ${ }^{8}$

— La Confederación mantendrá equilibrados sus ingresos y sus gastos de manera permanente.

- El techo total del gasto deberá ser fijado en los presupuestos en función de los ingresos estimados, teniendo en cuenta la situación coyuntural.

- Necesidades financieras excepcionales pueden justificar un incremento del techo de gasto, pero ello requerirá la aprobación por parte de las dos Cámaras del parlamento federal por mayoría absoluta de los miembros de cada Cámara (según establece el Art. 159.3.c de la Constitución federal).

- Si el gasto total de las cuentas del Estado sobrepasa el techo de gasto fijado en el presupuesto, este gasto excesivo deberá ser compensado en los presupuestos anuales sucesivos.

- Los detalles concretos del desarrollo de estas previsiones será regulado por ley.

Las previsiones del nuevo Art. 126 de la Constitución suiza entraron en vigor e el año 2003.

Observada la situación en su conjunto, y dejando aquí a un lado los precedentes descritos, nos encontramos, pues, por un lado, con Estados miembros de la UE que han afrontado la tarea de reformar sus respectivas Constituciones, a efectos de introducir en su texto la regla del equilibrio presupuestario, y que han concluido con éxito esta operación (Alemania, España, Italia), y, por otro, con Estados que, a pesar de haberlo intentado, han fracasado en el intento, fundamentalmente por motivos políticos, por carecer de los apoyos parlamentarios necesarios (Francia, Austria, Bulgaria). Entre estos últimos casos, destaca el caso de Austria, por cuanto, si bien no logró llevar la reforma prevista a la Constitución, sí, en cambio, logró aprobar esa reforma e introducirla en su ordenamiento jurídico a través de una ley ordinaria que recoge prácticamente al pié de la letra lo que se había previsto para la Constitución federal.

En las líneas que siguen se describen y analizan estos casos con detalle.

7 El referéndum tuvo lugar el 2 de diciembre de 2001 y el porcentaje de síes fue extraordinariamente alto $(84,7 \%)$, sobre todo si se tiene en cuenta que en ese referéndum se consultaba a los ciudadanos también sobre otras cuestiones de gran relevancia y atractivo popular (además del «frein à l'endettement», también «taxer l'énergie et non le travail», "une Suisse sans armée», "un service civil volontaire pour la paix», "un impôt sur les gains en capital»), en todas las cuales el resultado fue negativo, si bien la participación fue muy baja (37,82\%). (Arrêté du Conseil fédéral, du 4 février 2002, constatant le résultat de la votation populaire du 2 décembre 2001).

8 Vid. Constitution fédérale de la Confédération suisse du 18 avril 1999 (état le 11 mars 2012). 


\section{A) Alemania}

Hubo que esperar casi veinte años, tras las previsiones del Tratado de Maastricht, para que un Estado miembro de la UE introdujese en su Constitución la «regla de oro» de la estabilidad presupuestaria: este país fue Alemania, en el año 2009. ${ }^{9}$ La decisión fue adoptada por el Gobierno de gran coalición entre los socialistas del SPD y los cristiano-demócratas de la CDU-CSU, presidido por Angela Merkel. La reforma constitucional fue, en realidad, el último acto importante del Gobierno de gran coalición, dado que, poco después, las elecciones del 27 de septiembre de 2009 dieron la victoria a la Unión Cristiano Democrática y a su socia, la Unión Cristiano Social de Baviera (CDU-CSU), las cuales formaron un Gobierno de coalición con el partido liberal —Partido Libre Democrático (FDP)— de nuevo bajo la presidencia de Angela Merkel.

La enmienda $n^{\circ}$ 57, del 29 de julio de 2009, aprobada por el Bundestag el 30 de mayo, y por el Bundesrat el 12 de junio, afectó a siete artículos de la Ley Fundamental (Arts. 91c, 91d, 104b, 109, 109a, 115, 143d), estableciendo una normativa muy detallada y extensa sobre la exigencia de estabilidad presupuestaria. Así, en esencia, la nueva formulación de la Ley Fundamental establece en este terreno lo siguiente:

— La Federación y los Estados (Länder) respetarán, de manera general, el principio de equilibrio en la gestión de sus presupuestos (Art. 109.2 y 3), asegurando el equilibrio entre gastos e ingresos, excluidos los créditos (Arts. 109.3, 115.2). Se entiende, sin embargo, que este último principio se cumple si el porcentaje de los créditos no excede el $0,35 \%$ de PIB. En todo caso, las deudas que superen el $1,5 \%$ del PIB deberán ser reducidas en el mismo ciclo económico. A estos efectos, se prevé la creación de una cuenta de control que documentará las desviaciones del porcentaje admisible de endeudamiento anual y que deberá ser equilibrada en un plazo medio (Art. 115.2).

- Una ley de la Federación deberá regular los detalles del equilibrio entre ingresos y gastos y el procedimiento para el cálculo del límite anual de endeudamiento, teniendo en cuenta el ciclo económico. Estos límites sólo podrán ser excedidos, mediante autorización expresa del Bundestag, en casos de catástrofes o de emergencias excepcionales que transciendan la capacidad de control del Estado y que tengan un grave impacto negativo en las finanzas públicas. En todo caso, estas medidas excepcionales deberán ser adoptadas junto con un plan de amortización de los gastos extraordinarios (Arts. 109.3, 115.2). ${ }^{10}$

9 Enmienda a la Ley Fundamental (Constitución federal) n 57 de 29 de julio de 2009 (Bundesgesetzblatt, I, 29.7.09, pág. 2248, en vigor: 1.8.09). La enmienda n 57, además de las previsiones presupuestarias que aquí se detallan, incluía también otras dos reformas: el nuevo Art. 91c, sobre sistemas de tecnologías de la información, que establece la cooperación entre la Federación y los Länder en la planificación, instalación y gestión de estos sistemas; y el nuevo Art. 91d, sobre cooperación administrativa, que establece la posibilidad de que la Federación y los Länder realicen estudios comparativos sobre el funcionamiento de sus administraciones y hagan públicos sus resultados.

10 La ley de la Federación que desarrolla las previsiones constitucionales de equilibrio presupuestario es la Ley de10 de agosto de 2009 (Bundesgesetzblatt, I, pág. 2702). 
En estas misma línea, se establece también que, en esos casos de catástrofes naturales o de situaciones excepcionales de emergencia, la Federación puede prestar apoyo financiero a los Länder, incluso cuando carezca de competencia legislativa para ello (Art. 104b.1, para. 2).

- La Federación y los Länder pueden adoptar reglas para equilibrar las cuentas entre períodos de bonanza y períodos de escasez dentro de los ciclos económicos que se desvíen de la normalidad (Art. 109.3).

- La adquisición de préstamos, garantías u otros compromisos que supongan gasto en años fiscales futuros requiere la autorización de la Federación, la cual deberá especificar las cantidades máximas previstas y su cómputo (Art. 115.1).

- Se prevé que, por ley de la Federación, se establecerá un control continuo de la gestión presupuestaria de la Federación y de los Länder mediante un nuevo organismo, que se crea al efecto, denominado Consejo de Estabilidad (Art. 109a.1)

- Se establece que se regularán por ley las condiciones y el procedimiento para la declaración de una inminente emergencia presupuestaria (Art. 109a.2), así como los principios que rijan el establecimiento y aplicación de los programas de restructuración tendentes a evitar las situaciones de emergencia presupuestaria (Art. 109a.3).

- Se establece que las sanciones que establezca la UE en aplicación del Art. 126 del Tratado de Funcionamiento de la Unión Europea, sobre la observancia de la disciplina presupuestaria, serán cubiertas en un $65 \%$ por la Federación y en un $35 \%$ por los Länder (Art. 109.5). ${ }^{11}$

- La enmienda n 57 prevé una graduación de los plazos para la plena entrada en vigor de las previsiones mencionadas. Así, si bien el proceso de adaptación de los presupuestos al principio de estabilidad financiera comenzó ya en el año 2011, la plena adecuación a estas reglas deberá conseguirse, en el caso de los presupuestos de la Federación, en el año 2015, y en el caso de los presupuestos de los Länder, en el año 2020 (Art. 143d.1).

- En esta línea, se establece asimismo que los pasos concretos a dar en la reducción del déficit, en esta adaptación a la nueva exigencia constitucional, su supervisión por el Consejo de Estabilidad y las sanciones en caso de incumplimiento serán fijadas por ley de la Federación y por un acuerdo administrativo entre la Federación y los Länder (Art. 143d.2)

- La enmienda $n^{\circ} 57$, en fin, establece previsiones especiales de apoyo financiero para algunos de los Länder, a efectos de facilitar su adaptación al nuevo plan de equilibrio financiero (Art. 143d.2). ${ }^{12}$

11 Es sorprendente observar como, en la reforma de este precepto, la enmienda $\mathrm{n}^{\circ} 57$ mantiene las referencias a la vieja normativa de la Unión, previa a la entrada en vigor del Tratado de Lisboa. Así, este precepto — que aquí se cita adaptado ya al Tratado de Lisboa— se refiere, de manera errónea, al Art. 104 (hoy 126) del Tratado de la Comunidad Europea (hoy TFUE) y a la Comunidad Europea, hoy inexistente.

12 Sin embargo, se establece igualmente que el peso de esta consolidación financiera especial recaerá al cincuenta por cien entre la Federación y los Länder, haciendo que estos últimos financien su parte con cargo al impuesto sobre el valor añadido (Art. 143d.3 de la Ley Fundamental). 


\section{B) Francia}

El segundo Estado de la UE que optó por la reforma constitucional para introducir las reglas de equilibrio presupuestario fue Francia. De hecho, el entonces Presidente de la República, Nicolas Sarkozy, actuaba de común acuerdo con la Canciller alemana, Angela Merkel, con el mismo objetivo de lograr el pleno reequilibrio de las finanzas públicas en el seno de la eurozona, principalmente, pero también en el conjunto de la UE, a través de una exigente política de austeridad financiera. El Presidente Sarkozy, gracias a su mayoría parlamentaria, logró que su proyecto de reforma constitucional fuese aprobado por la Asamblea Nacional y por el Senado, prácticamente con el mismo texto propuesto, pero no logró superar la última fase del proceso: la aprobación de ese mismo texto, bien en referéndum por los ciudadanos franceses, o bien por el conjunto del Parlamento francés, reunido en Congreso, de acuerdo con las previsiones del Art. 89 de la Constitución francesa de 1958. Así, por un lado, el Presidente Sarkozy no se atrevió a someter este tipo de normativa al referéndum de los ciudadanos franceses, por temor al fracaso, como ya había ocurrido con el referéndum sobre la Constitución de la Unión Europea, el 29 de mayo de 2005; y, por otro lado, el Art. 89 de la Constitución francesa exige —en caso de que el Presidente de la República decida someter un texto de reforma de la Constitución al Parlamento convocado en Congreso-, que éste obtenga el voto favorable de las tres quintas partes de los votos expresados, cosa que la mayoría parlamentaria del grupo del Presidente Sarkozy no alcanzaba en aquel momento.

La reforma constitucional francesa era también extensa e iba a afectar a doce artículos (modificaba los Arts. 34, 39, 42, 47, 47.1, 47-2, 48, 49, 61, 70, e insertaba los Arts. 46-1 y 88-8). ${ }^{13}$ En sustancia, la reforma giraba en torno a un nuevo tipo de norma jurídica que se introducía en el ordenamiento jurídico francés por primera vez: la «loi-cadre d'équilibre des finances publiques». Este nuevo tipo de norma era, en realidad, un tipo especial de «loi organique», formulado para períodos de, al menos, tres años, y cuyo objeto era regular las orientaciones plurianuales y las normas de evolución y gestión de las finanzas públicas, con el objetivo de «assurer l'équilibre des comptes des administrations publiques». El objetivo era fijar para cada año un techo de gasto que se impondría de manera general a las leyes de finanzas y a las leyes de financiación de la seguridad social. Ninguna ley de finanzas - presupuestos generales, leyes de financiación de la seguridad social, etc.- - podría ser aprobada sino dentro del marco general previo de una ley-cuadro de finanzas públicas. Por otra parte, cualquier proyecto de ley de finanzas debía ser presentado previamente al Consejo Constitucional, para que éste pudiese pronunciarse sobre su adecuación a la ley-cuadro de finanzas públicas correspondiente.

Las leyes-cuadro de finanzas públicas tendrían, pues, un rango superior a las leyes ordinarias, y muy específicamente con respecto a las leyes de finanzas y a las leyes de financiación de la seguridad social, que debían adaptarse a las primeras. Las leyes-cuadro de finanzas públicas tendrían el carácter de leyes orgánicas y, como tales, sólo podrían ser modificadas o derogadas mediante otra ley-cuadro de finanzas públicas, y su elaboración

13 Projet de loi constitutionnelle relatif à l'équilibre des finances publiques. Texte adopté $\mathrm{n}^{\circ} 722$ rect. "petite loi» (Assemblée Nationale, treizième législature, session extraordinaire de 2010-2011, 13 juillet 2011). 
tenía que hacerse a través del mismo procedimiento que las leyes orgánicas (Art. 46 de la Constitución).

En fin, el proyecto frustrado de reforma de la Constitución francesa preveía también la formulación del «programme de stabilité» francés y su coordinación con las políticas económicas de los demás Estados miembros de la UE (Art. 88.8 de la Constitución).

El fracaso del Presidente Sarkozy en las elecciones presidenciales del 22 de abril y del 6 de mayo de 2012, y el triunfo del candidato socialista, François Hollande — que era claramente contrario a las políticas de austeridad promovidas por Sarkozy y Merkel—, añadido al triunfo de la izquierda en las elecciones parlamentarias que tuvieron lugar poco tiempo después, los días 10 y 17 de junio de 2012, supuso el abandono del proyecto de reforma constitucional, sin que, por lo de ahora, el nuevo Presidente francés haya adoptado ninguna medida específica en esta línea.

\section{C) España}

El tercer Estado miembro de la UE en afrontar la reforma de su propia Constitución a efectos de introducir la regla de oro del equilibrio presupuestario fue España. En esta misma revista se introducen varios artículos que analizan la reforma constitucional española desde varias perspectivas. No es, pues, el objeto de este trabajo el entrar en profundidad en el análisis de esta reforma, sino simplemente ubicarla en el contexto de las reformas constitucionales de los Estados miembros y de la gobernanza de la UE que se produce en ese momento.

El proyecto de reforma constitucional español fue el producto de un pacto político entre el Presidente del Gobierno, José Luis Rodríguez Zapatero, líder indiscutido entonces del PSOE, y Mariano Rajoy presidente del PP, principal partido de la oposición, concluido en agosto de 2011. El texto de la reforma se presentó como una proposición de reforma del artículo 135 de la Constitución española, presentada por los grupos parlamentarios Socialista y Popular en el Congreso, ${ }^{14}$ y su trámite parlamentario se realizó a través del procedimiento de tramitación directa y en lectura única, en virtud de lo dispuesto en el Art. 150 del Reglamento del Congreso de los Diputados. ${ }^{15}$

Todo ello, las circunstancias verdaderamente excepcionales y el modo en como se produjo esta reforma constitucional, ha producido - como ya se dijo al inicio de este trabajo- un duro debate político y fuertes críticas en algunos sectores de la doctrina constitucionalista. Pero, una vez más, no es tampoco el objeto de este trabajo el análisis de estos aspectos de la reforma. Baste mencionar aquí, al objeto del análisis comparativo, el contenido sustancial de la misma.

14 BOCG. Congreso de los Diputados, serie B, número 329-1, de 26 de agosto de 2011, pág. 2 (número de expediente 100/000001).

15 Vid. lo referente a la toma en consideración de la proposición de reforma del Art. 135 de la Constitución en Cortes Generales-Diario de Sesiones del Congreso de los Diputados-Pleno y Diputación Permanente, Año 2011, IX Legislatura, Núm. 269, Sesión plenaria núm. 255 (Sesión extraordinaria) celebrada el martes, 30 de agosto de 2011, págs. 2-23. Y lo referente a la votación y aprobación de la proposición de reforma, en Cortes Generales-Diario de Sesiones del Congreso de los Diputados-Pleno y Diputación Permanente, Año 2011, IX Legislatura Núm. 270, Sesión plenaria núm. 256, celebrada el viernes, 2 de septiembre de 2011, págs. 2-19. 
Así, la reforma del Art. 135 de la Constitución Española ${ }^{16}$ es menos extensa y detallada que las reformas alemana e italiana y, desde luego, menos alambicada, que la que se había propuesto para la Constitución francesa. En concreto, reforma del Art. 135 establece lo siguiente:

- Todas las Administraciones Públicas adecuarán sus actuaciones al principio de estabilidad presupuestaria.

- El Estado y las Comunidades Autónomas no podrán incurrir en un déficit estructural que supere los márgenes establecidos, en su caso, por la Unión Europea para sus Estados Miembros. Una ley orgánica fijará el déficit estructural máximo permitido al Estado y a las Comunidades Autónomas, en relación con su producto interior bruto.

- Las Entidades Locales deberán presentar equilibrio presupuestario.

- El Estado y las Comunidades Autónomas habrán de estar autorizados por ley para emitir deuda pública o contraer crédito. ${ }^{17}$

- Los créditos para satisfacer los intereses y el capital de la deuda pública de las Administraciones se entenderán siempre incluidos en el estado de gastos de sus presupuestos y su pago gozará de prioridad absoluta. Estos créditos no podrán ser objeto de enmienda o modificación, mientras se ajusten a las condiciones de la ley de emisión. ${ }^{18}$

- El volumen de deuda pública del conjunto de las Administraciones Públicas, en relación con el producto interior bruto del Estado, no podrá superar el valor de referencia establecido en el Tratado de Funcionamiento de la Unión Europea.

- Los límites de déficit estructural y de volumen de deuda pública sólo podrán superarse en caso de catástrofes naturales, recesión económica o situaciones de emergencia extraordinaria que escapen al control del Estado y perjudiquen considerablemente la situación financiera o la sostenibilidad económica o social del Estado, apreciadas por la mayoría absoluta de los miembros del Congreso de los Diputados.

- Una ley orgánica desarrollará los principios a que se refiere este artículo. De manera específica, esta ley orgánica regulará lo siguiente: a) la participación, en los procedimientos respectivos, de los órganos de coordinación institucional entre las Administraciones Públicas en materia de política fiscal y financiera; $b$ ) la distribución de los límites de déficit y de deuda entre las distintas Administraciones Públicas; c) los supuestos excepcionales de superación de los mismos; d) la forma y plazo de corrección de las desviaciones que sobre uno y otro pudieran producirse; $e$ ) la metodología y el procedimiento para el cálculo del déficit estructural; y f) la responsabilidad de cada Administración Pública en caso de incumplimiento de los objetivos de estabilidad presupuestaria.

16 Reforma del artículo 135 de la Constitución Española, de 27 de septiembre de 2011 (BOE Núm. 233, 27 de septiembre de 2011, pág. 101931).

17 Este apartado del precepto se limita a añadir a las Comunidades Autónomas, que no eran mencionadas en la redacción original del Art. 135.1.

18 Este apartado del precepto, de redacción igual a la original, se limita a añadir la frase «su pago gozará de prioridad absoluta». 
- Las Comunidades Autónomas adoptarán las disposiciones que procedan para la aplicación efectiva del principio de estabilidad en sus normas y decisiones presupuestarias.

En desarrollo de las previsiones del nuevo Art. 135, se formuló la Ley Orgánica 2/2012, de 27 de abril, de Estabilidad Presupuestaria y Sostenibilidad Financiera, que regula los aspectos mencionados en su párrafo $5 .{ }^{19}$

D) Italia

El cuarto Estado miembro de la UE que introdujo una reforma de su Constitución a efectos de establecer la regla del equilibrio presupuestario - y el último que lo ha hecho hasta el momento de cerrar este trabajo — fue Italia. La reforma italiana fue inicialmente propuesta por el Gobierno Berlusconi, el 13 de abril de 2011, pero, tras su sustitución por Mario Monti, el 16 de noviembre de 2011, el nuevo Gobierno mantuvo la iniciativa y la reforma fue finalmente aprobada por el Parlamento el 18 de abril de 2012.

La reforma constitucional italiana no es tan extensa y prolija como la alemana, si bien afecta a cuatro artículos del texto constitucional (Arts. 81, 97, 117 y 119). La reforma, realizada por la Legge Costituzionale 20 aprile 2012, n. 1. Introduzione del principio del pareggio di bilancio nella Carta costituzionale, ${ }^{20}$ incluye, en realidad, dos ámbitos diferentes: uno referido materialmente a la reforma de los artículos mencionados de la Constitución, y otro referido al desarrollo normativo posterior — cuyos principios básicos la propia Legge Costituzionale n. 1/2012 fija con detalle-, que ha de realizarse por una ley que ha de ser aprobada antes del 28 de febrero de 2013.

En sustancia, y en lo que se refiere a la reforma constitucional en sentido estricto, la Legge Costituzionale n. 1/2012 establece lo siguiente:

- Las administraciones públicas aseguran el equilibrio presupuestario y la sostenibilidad de la deuda pública, de acuerdo con el ordenamiento de la Unión Europea (Art. 97 de la Constitución).

- El Estado asegura en su presupuesto el equilibrio entre ingresos y gastos, teniendo en cuenta las fases adversas y las fases favorables del ciclo económico (Art. 81).

- El recurso al endeudamiento es muy restringido: requiere la autorización de la Cámara de Diputados, por mayoría absoluta de sus componentes, y en caso de eventos excepcionales (Art. 81).

- Las Cámaras han de aprobar cada año la ley de presupuestos y la rendición de cuentas del período presentada por el Gobierno (Art. 81).

- Se establece que el contenido básico de la ley de presupuestos, las normas fundamentales y los criterios referidos al aseguramiento del equilibrio entre ingresos y gastos y la sostenibilidad de la deuda del conjunto de las administraciones públicas será establecido por una ley, aprobada por mayoría absoluta de

19 Ley Orgánica 2/2012, de 27 de abril, de Estabilidad Presupuestaria y Sostenibilidad Financiera (BOE Núm. 103, 30 de abril de 2012, pág. 32653.

20 Legge Costituzionale 20 aprile 2012, n. 1. Introduzione del principio del pareggio di bilancio nella Carta costituzionale (12G0064) (Gazzetta Ufficiale n. 95 del 23.4.2012). 
los componentes de cada una de las Cámaras (Art. 81). La misma Legge Costituzionale $n$. 1/2012 establece en su Art. 5 cual ha de ser el contenido sustantivo de esta ley especial.

- Toda ley que implique nuevos o mayores gastos debe proveer los medios para hacerles frente (Art. 81).

- Se obliga a las autoridades locales, provinciales y regionales al respeto del principio de equilibrio en sus respectivos presupuestos y al respeto también de las disposiciones económicas y financieras derivadas del ordenamiento de la UE (Art. 119).

Y, en lo que se refiere a la ley especial de desarrollo de las previsiones constitucionales de equilibrio presupuestario, la Legge Costituzionale n. 1/2012 establece lo siguiente:

- La ley a la que se refiere ahora el nuevo Art. 81 de la Constitución debe fijar, entre otras cosas, lo siguiente: a) la verificación previa y de cierre de las cuentas de las finanzas públicas; $b$ ) la comprobación de las causas de las desviaciones con respecto a las previsiones realizadas, distinguiendo entre las debidas a la evolución del ciclo económico, a la ineficacia de los gestores, o a eventos excepcionales; c) el limite máximo de desviación negativa con respecto a las previsiones realizadas para cada ciclo económico y con respecto al PIB, para cuya superación sean necesarias medidas de corrección; d) la definición de las situaciones de grave recesión económica, de crisis financiera y de desastres naturales que justifiquen el recurso excepcional al endeudamiento; e) la introducción de reglas de gasto que permitan respetar el equilibrio presupuestario y la reducción del porcentaje de déficit público con respecto al PIB a largo plazo; $f$ ) el establecimiento de un organismo independiente para el análisis y verificación de las finanzas públicas y la observación de las reglas de equilibrio presupuestario; g) las formas a través de las cuales el Estado puede asegurar la financiación de los otros niveles de gobierno y de las funciones básicas referidas a las prestaciones esenciales inherentes a los derechos civiles y sociales, en las fases adversas del ciclo económico, o en situaciones excepcionales graves; $h$ ) el contenido básico de la ley de presupuestos del Estado; i) la facultad de las autoridades locales, provinciales y regionales, y de las provincias autónomas de Trento y de Bolzano, de recurrir al endeudamiento para gastos de inversión; y, en fin, j) la forma en la cual las autoridades locales, provinciales y regionales, y de las provincias autónomas de Trento y de Bolzano, concurren a la sostenibilidad de la deuda del conjunto de las administraciones públicas.

- Además de la creación del mencionado organismo independiente para el análisis y control de las cuentas públicas, se obliga, de forma específica, a las Cámaras parlamentarias a ejercer, de acuerdo con sus propios reglamentos, la función de control de las finanzas públicas, con especial atención al equilibrio entre ingresos y gastos y a la calidad y eficacia del gasto de las administraciones públicas.

- Esta ley especial — que ha ser aprobada por mayoría absoluta de los componentes de cada una de las Cámaras, según lo previsto en el nuevo Art. 81 de la Constitución_- deberá ser aprobada antes del 28 de febrero de 2013. 
Finalmente, cabe decir que, de acuerdo con su Art. 6, las previsiones de la Legge Costituzionale n. 1/2012, de reforma de la Constitución italiana de 1948, se aplicarán plenamente a partir del ejercicio financiero del año 2014.

E) Balance

Las regulaciones de las reformas constitucionales analizadas no son exactamente iguales, ni en su extensión ni en la forma de su regulación. Sin embargo, sí se puede decir que son muy similares en el contenido material de sus previsiones.

Por otra parte, llama la atención el hecho mismo de que, a pesar del amplio movimiento político que, a lo largo de los años 2010 y 2011, impulsaba las reformas constitucionales como el mejor instrumento para asegurar la estabilidad financiera y presupuestaria de los Estados miembros de la UE, solamente tres Estados - Alemania, España e Italiahayan logrado llevar adelante tal reforma constitucional. En los demás casos, las reformas se han realizado sólo a través de la legislación ordinaria y, cabe decir también, que ni siquiera en todos los casos los Estados miembros de la UE han sido — están siendo- muy diligentes a la hora de formular y realizar estas reformas, en línea con las directrices emanadas de la UE.

De las reformas constitucionales analizadas se deduce que cuatro son los aspectos previstos en todos los casos:

- La exigencia de un equilibrio presupuestario claro entre ingresos y gastos, para todos los niveles de gobierno y/o de las administraciones públicas.

- La remisión a una norma posterior — de rango variado en los diferentes casosde la regulación detallada de los términos, plazos, límites y excepciones de la consecución y mantenimiento de este equilibrio financiero.

- La exigencia de una ley del Estado para la admisión de fórmulas de endeudamiento por parte, tanto del mismo Estado, como de los demás niveles inferiores de gobierno.

- La admisión de excepciones al cumplimiento de esta regla general de equilibrio presupuestario y, por lo tanto, de niveles de endeudamiento superior, en casos excepcionales de catástrofes naturales u otro tipo de situaciones excepcionales de emergencia económica.

Otros aspectos relevantes, en cambio, no son recogidos de manera igual en las tres reformas constitucionales mencionadas. Así, en primer lugar, la reforma alemana y la reforma italiana incluyen también en la Constitución la previsión de un nuevo organismo autónomo para el control de la aplicación de este principio de estabilidad financiera, que, en el caso español, se remite a la legislación posterior.

En segundo lugar, ni en el caso español, ni en el caso italiano se recogen referencias explícitas a los porcentajes admisibles de déficit o de deuda públicos, que sí se establecen, en cambio, en el caso de la reforma alemana.

Y, en tercer lugar, en el caso español y en el caso italiano, en cambio, se recogen referencias explícitas a las directrices de la UE, o a los valores de referencia de déficit y de deuda públicos establecidos en el Tratado de Funcionamiento de la Unión Europea; cosa que no se recoge en la reforma alemana. Esta última, sin embargo, sí menciona y regula las consecuencias de una imposición de sanciones por parte de la UE, en el caso de incumplimiento de la disciplina presupuestaria. 


\section{LAS REFORMAS DE LA GOBERNANZA ECONÓMICA DE LA UNIÓN EUROPEA}

Las reformas de la gobernanza económica de la Unión Europea se han producido en los últimos años a través de la combinación de una serie de instrumentos político-estratégicos y de instrumentos jurídicos. Es verdad, sin embargo, que estos instrumentos están íntimamente enlazados entre sí, en todos los casos, lo que hace muy difícil precisar, en términos exclusivos, el perfil jurídico, o el perfil político-estratégico, de cada uno de ellos.

Así, como instrumentos político-estratégicos, podemos mencionar los siguientes:

- El Pacto de Estabilidad y Crecimiento, de 1997, en su dimensión estratégica

- La estrategia Europa 2020, del año 2010.

- El Semestre Europeo, del año 2010.

- El Pacto Euro Plus, del año 2011.

$\mathrm{Y}$, como instrumentos jurídicos, debemos mencionar los siguientes:

- El Pacto de Estabilidad y Crecimiento, de 1997, en su dimensión jurídica, reforzado en 2005 y en 2011.

- El Art. 126 TFUE y su desarrollo por el Protocolo ( $\left.n^{\circ} 12\right)$ sobre el procedimiento aplicable en caso de déficit excesivo.

- La reforma del Art. 136 TFUE y su desarrollo a través del Tratado constitutivo del Mecanismo Europeo de Estabilidad (MEDE), de 2011 (modificado en 2012).

— El denominado paquete de seis medidas ( "The Six Pack»), de 2011.

- El denominado paquete de dos medidas ( $T$ The Two Pack»), cuyos proyectos de la Comisión se encuentran aún en estudio.

- El Tratado de Estabilidad, Coordinación y Gobernanza en la Unión Económica y Monetaria («pacto fiscal»), de 2012.

A) Los instrumentos estratégicos

\section{i) El Pacto de Estabilidad y Crecimiento}

El Pacto de Estabilidad y Crecimiento de 1997 es, a la vez, un documento estratégico y un conjunto normativo. Así, el Pacto crea el cuadro general para el adecuado funcionamiento de la Unión Económica y Monetaria, estableciendo un marco jurídico para la supervisión de la gestión de las finanzas públicas de los Estados miembros de la UE. El crecimiento excesivo de la deuda soberana de los Estados en los años que siguieron, demostró inmediatamente que las previsiones del Pacto eran insuficientes, o inadecuadas, lo que llevó pronto a su revisión y reforzamiento en 2005 y, más recientemente, en 2011.

La primera formulación del Pacto de Estabilidad y Crecimiento se realizó mediante la Resolución del Consejo sobre el Pacto de Estabilidad y Crecimiento, Ámsterdam, 17 de junio de 1997 (97/C 236/01). ${ }^{21}$ Y su desarrollo normativo se realizó mediante el Re- 
glamento (CE) n $\mathrm{n}^{\circ}$ 1466/97, del Consejo, de 7.7.1997, relativo al reforzamiento de la supervisión de las situaciones presupuestarias y a la supervisión y coordinación de las políticas económicas, y el Reglamento (CE) no 1467/97, del Consejo, de 7.7.1997, relativo a la aceleración y clarificación del procedimiento de déficit excesivo. ${ }^{22}$ La revisión del Pacto y de su contenido normativo se realizó mediante una Comunicación de la Comisión, ${ }^{23}$ y la formulación de dos nuevos reglamentos de 27 de junio de 2005 , que vienen a reformar a los dos anteriores de $1997 .{ }^{24}$ En esencia, el nuevo Pacto de Estabilidad y Crecimiento a) establece objetivos a medio plazo diferenciados para cada Estado, teniendo en cuenta sus circunstancias económicas y presupuestarias específicas, para llegar al valor de referencia de déficit del 3\% del PIB previsto por el Art. 126 del TFUE y el Protocolo $\mathrm{n}^{\circ} 12$ sobre el procedimiento aplicable en caso de déficit excesivo; exige lograr un ajuste estructural anual del $0,5 \%$ del PIB; y $b$ ) exige que los ajustes fiscales sean verdaderamente de carácter estructural, excluyendo las medidas excepcionales o con efectos meramente temporales. Estas previsiones serían modificadas y reforzadas aún una vez más - con un sistema de sanciones económicas para los Estados incumplidores-, en noviembre de 2011, por otros dos nuevos reglamentos de reforma. ${ }^{25}$

\section{ii) Europa 2020}

Europa 2020 es la nueva estrategia, adoptada por el Consejo Europeo de 17 de junio de 2010, que viene a sustituir a la fracasada Estrategia de Lisboa, de 24 de marzo de 2000. La nueva estrategia se centra ahora en tres prioridades, para lograr un «crecimiento inteligente, sostenible e integrador». Estas prioridades son transversales y, por tanto, deben inspirar toda la actuación de la UE en las diversas áreas de su competencia. Así, se trata de lograr:

- un crecimiento inteligente: desarrollo de una economía basada en el conocimiento y la innovación.

- un crecimiento sostenible: una economía más eficaz en el uso de los recursos, más verde y competitiva.

- un crecimiento integrador: una economía con alto nivel de empleo que promueva la cohesión social y territorial.

Además, se establecen metas específicas para el empleo, la innovación, el clima, la energía, la educación y la inclusión social.

22 Diario Oficial L 209, 2.8.1997

23 Comunicación de la Comisión, Reforzamiento de la gobernanza económica y mejora de la aplicación del Pacto de Estabilidad y Crecimiento (Bruselas, 3.9.2004, COM(2004) 581 final).

24 Reglamento (CE) no 1055/2005, del Consejo, de 27 de junio de 2005, por el que se modifica el Reglamento (CE) n 1466/97 del Consejo (DO L 174, 7.7.2005), y Reglamento (CE) n ${ }^{\circ}$ 1056/2005 del Consejo, de 27 de junio de 2005, por el que se modifica el Reglamento (CE) n ${ }^{\circ}$ 1467/97 del Consejo (DO L 174, 7.7.2005).

25 Se trata de dos reglamentos que forman parte del paquete de seis normas jurídicas conocidas como «the six pack»: el Reglamento (UE) $\mathrm{n}^{\circ}$ 1175/2011 del Parlamento Europeo y del Consejo, de 16.11.2011, por el que se modifica el Reglamento (CE) n ${ }^{\circ}$ 1466/97 del Consejo, relativo al refuerzo de la supervisión de las situaciones presupuestarias y a la supervisión y coordinación de las políticas económicas; y el Reglamento (UE) $n^{\circ}$ 1177/2011 del Consejo, de 8.11.2011, por el que se modifica el Reglamento (CE) no 1467/97, relativo a la aceleración y clarificación del procedimiento de déficit excesivo. 
En todo caso, si bien se trata de un documento estratégico que enmarca y determina toda la actuación de la UE, Europa 2020 es un documento puramente político, carente de valor jurídico, y, por lo tanto, no merece mas desarrollo analítico en este trabajo. Baste, pues, su sola mención como documento de referencia.

\section{iii) El Semestre Europeo}

El Semestre Europeo - al igual que Pacto de Estabilidad y Crecimiento, al cual completa - es a la vez un documento estratégico y un conjunto normativo, si bien, en este caso, de normas de carácter adjetivo, dirigidas a regir el proceso de coordinación de las políticas económicas y presupuestarias de la Unión y de sus Estados miembros. El Semestre Europeo es un paso adelante más en esta línea de refuerzo de la supervisión de la actuación de los Estados en la formulación y aplicación de sus políticas económicas y presupuestarias. Fue aprobado por el Ecofin, el 7 de septiembre de 2010, y consiste, en realidad, en una nueva programación sistemática y cronológica a) por un lado, de las actividades de coordinación, dirección y supervisión de la UE, analizando de manera conjunta las políticas económicas y las políticas fiscales; y b) por otro lado, de las actividades de formulación y desarrollo de sus políticas económicas y presupuestarias, así como de sus Programas de Estabilidad (en el caso de los Estados miembros de la eurozona), ${ }^{26}$ de sus Programas de Convergencia (en el caso de los demás Estados), ${ }^{27}$ y de sus Programas de Reforma, por parte de todos los Estados miembros.

El principal objetivo del Semestre Europeo es combinar la coordinación de la política presupuestaria, regida por el Pacto de Estabilidad y Crecimiento, con la coordinación de las políticas económicas, estructurales y de empleo, regidas por la estrategia de crecimiento Europa 2020. En este sentido, en el análisis y coordinación de las políticas económicas se incluye ahora también la consideración de los desequilibrios macroeconómicos, asuntos financieros sectoriales y las reformas estructurales para el crecimiento. Así, de acuerdo con este esquema, el primer semestre del año —el semestre europeo- se dedica a la formulación por parte de la UE de las directrices económicas conjuntas para los Estados, y el segundo semestre —el semestre nacional— se dedica a la supervisión de la actuación de los Estados en la aplicación de esas líneas directrices en la formulación y aplicación de sus propias políticas económicas y presupuestarias, así como de los mencionados Programas de Estabilidad, o Programas de Convergencia, y los Programas de Reforma. El Semestre Europeo comenzó a operar en enero de 2011.

\section{iv) El Pacto Euro Plus}

Y, en fin, el Pacto Euro Plus, aprobado por los Jefes de Estado o de Gobierno de la Eurozona, el 11 de marzo de 2011, incluye a los 17 Estados de la eurozona, a los que se han unido otros seis Estados más, no pertenecientes al euro (Bulgaria, Dinamarca, Leto-

26 De acuerdo con las Guidelines on the format and content of Stability and Convergence Programmes (o Code of Conduct).

27 Los Programas de Estabilidad y los Programas de Convergencia se presentan a la Comisión y al ECOFIN generalmente en el mes de abril de cada año. 
nia, Lituania, Polonia, Rumanía). El Pacto obliga a los signatarios a una coordinación económica más estrecha, también en áreas de competencia nacional, para conseguir una mayor convergencia y competitividad. Se trata de integrar plenamente en las legislaciones nacionales las previsiones fiscales del Pacto de Estabilidad y Crecimiento, y establecer para los Estados metas específicas, revisables anualmente por los Jefes de Estado o de Gobierno. El Pacto Euro Plus se integra dentro del Semestre Europeo y la Comisión supervisa el cumplimiento de sus objetivos.

B) Los instrumentos jurídicos

\section{i) El Art. 126 TFUE y el procedimiento aplicable en caso de déficit excesivo}

El Art. 126 del TFUE (antiguo artículo 104 del TCE) establece la regla general por la que los Estados miembros evitarán déficits públicos excesivos, y atribuye a la Comisión la supervisión de la evolución de la situación presupuestaria y del nivel de endeudamiento público de los Estados. En este sentido, a) se trata de que la proporción entre el déficit público previsto o real y el producto interior bruto (PIB) no sobrepase un valor de referencia, que el Tratado no fija, y $b$ ) se trata igualmente de que la proporción entre la deuda pública y el PIB no rebase un valor de referencia, que el Tratado tampoco fija. Estos valores de referencia son especificados en el Protocolo $\mathrm{n}^{\mathrm{o}} 12$ sobre el procedimiento aplicable en caso de déficit excesivo, anejo a los Tratados, el cual establece que hay déficit público excesivo cuando la proporción entre el déficit público y el PIB sobrepasa el valor de referencia del $3 \%$. Y entiende que hay deuda pública excesiva cuando la proporción entre la deuda pública y el PIB rebasa el valor de referencia del $60 \%$.

Lo interesante es destacar aquí como esta normativa es desarrollada por - y se integra con- la normativa de reforma de la gobernanza económica de la UE a la que nos referimos más adelante. Así, las previsiones del Art. 126 del TFUE y del Protocolo n 12 han sido desarrolladas por el Reglamento (CE) no $1467 / 97$, relativo a la aceleración y clarificación del procedimiento de déficit excesivo — que es parte sustantiva del Pacto de Estabilidad y Crecimiento, de 1997—; el Reglamento (CE) no 479/2009 del Consejo, de 25.5.2009, relativo a la aplicación del Protocolo sobre el procedimiento aplicable en caso de déficit excesivo, anejo al Tratado constitutivo de la Comunidad Europea, y el Reglamento (UE) $\mathrm{n}^{\circ} 1177 / 2011$ del Consejo, de 8.11.2011, por el que se modifica el Reglamento (CE) n ${ }^{\circ} 1467 / 97$, que son parte del conjunto normativo conocido como «The Six Pack».

\section{ii) La reforma del Art. 136 del TFUE y el Mecanismo Europeo de Estabilidad}

La reforma del Art. 136 del TFUE y la introducción de lo que luego pasará a ser denominado «Mecanismo Europeo de Estabilidad», como la reforma de la gobernanza económica de la UE en su conjunto, viene determinada por la grave crisis financiera que afecta a Europa a partir del año 2008. Así, a lo largo de los años 2010 y 2011, bajo la acuciante presión de los mercados de capitales y en medio de una gran tensión política, la UE logró poner en funcionamiento una serie de mecanismos de estabilización destinados a paliar la crisis y a atender a las necesidades extraordinarias de financiación de los 
Estados miembros en peligro, a los que nos referimos más adelante. ${ }^{28}$ Estos mecanismos fueron concebidos como medidas urgentes y temporales, para una duración máxima de tres años — hasta junio de 2013 — ${ }^{29}$ por lo que, dada la gravedad y la generalización de la crisis financiera, se hacía necesario — además de las medidas temporales_ revisar todo el sistema de gobernanza económica de la UE y reforzar de manera permanente los mecanismos de coordinación, responsabilidad y control de la actuación económica y financiera de los Estados miembros. En este sentido, la primera y más urgente medida a adoptar era el establecimiento de un mecanismo permanente de estabilización que pudiese conseguir y movilizar fondos y proveer asistencia financiera a los Estados de la zona euro en situación de grave crisis de liquidez, consiguiendo con ello dar garantías a los mercados de capitales y fortalecer de manera permanente el euro.

En esta línea, el Consejo Europeo de 28-29 de octubre de 2010, convino en la necesidad de que los Estados miembros estableciesen un mecanismo permanente de crisis para salvaguardar la estabilidad financiera de la zona del euro, e invitó al Presidente del Consejo Europeo a emprender consultas con los Estados miembros sobre una posible reforma del TFUE. La idea era que la reforma fuese limitada, para que no hubiese que abrir un procedimiento ordinario de reforma, con una Convención, una Conferencia Intergubernamental, etc. Para ello, se decidió optar por la vía del procedimiento simplificado de revisión que prevé el Art. 48.6 del TUE. Este precepto permite que, cuando la decisión de reforma se refiera a las disposiciones de la Tercera Parte del TFUE ( «Políticas y acciones internas de la Unión»), el Consejo Europeo adopte la decisión por sí solo, por unanimidad y previa consulta al Parlamento Europeo, a la Comisión y al Banco Central Europeo, por tratarse en este caso de una modificación institucional en el ámbito monetario.

El procedimiento formal de revisión del Tratado se inició — de acuerdo con este marco jurídico - con la proposición de reforma del Art. 136 del TFUE presentada por el Gobierno belga, el 16 de diciembre de 2010. Tras lo cual, el Consejo Europeo del 16 y 17 de diciembre de 2010 adoptó el acuerdo de modificar el Art. 136 del TFUE añadiéndole un nuevo párrafo — el 3- que establece lo siguiente: ${ }^{30}$

«3. Los Estados miembros cuya moneda es el euro podrán establecer un mecanismo de estabilidad que se activará cuando sea indispensable para salvaguardar la estabilidad de la zona del euro en su conjunto. La concesión de toda ayuda financiera necesaria con arreglo al mecanismo se supeditará a condiciones estrictas.»

Consultados el Parlamento Europeo, la Comisión Europea y el Banco Central Europeo, ${ }^{31}$ el Consejo Europeo de 24 y 25 Marzo 2011 adoptó finalmente la decisión formal

28 Así, el mecanismo de rescate de Grecia, aprobado por la reunión de Jefes de Estado de la Eurozona el 25 de marzo de 2010; el Mecanismo Europeo de Estabilización Financiera (MEEF / EFSM), mecanismo de la Unión para ayudar a todos los Estados miembros (Reglamento (UE) No 407/2010 del Consejo, de 11 de mayo de 2010, por el que se establece un mecanismo europeo de estabilización financiera, DO L 118, 12.5.2010), y el Fondo Europeo de Estabilidad Financiera (FEEF / EFSF), sociedad anónima constituida por y para los Estados miembros de la Eurozona (EFSF Framework Agreement, 19.10.2011), aprobados por la reunión extraordinaria del Ecofin, de 9-10 de mayo de 2010.

29 La financiación prestada, en cambio, lo fue inicialmente para siete años.

30 Consejo Europeo de 16 y 17 de diciembre de 2010, Conclusiones-Anexo I (EUCO 30/1/10, Bruselas, 17 diciembre 2010).

31 Vid. dictamen del Parlamento Europeo de 23 de marzo de 2011, dictamen de la Comisión Europea de 15 de febrero de 2011, y dictamen del Banco Central Europeo de 17 de marzo de 2011. 
de modificar el Art. 136 del TFUE en los términos previstos y de permitir así la creación de lo que se denomina ahora «Mecanismo Europeo de Estabilidad» (MEDE / ESM). ${ }^{32}$ El Mecanismo Europeo de Estabilidad — de acuerdo con las previsiones del Consejo Europeo- debería ser una entidad de carácter intergubernamental, con sede en Luxemburgo, cuya función es la de proveer asistencia financiera a los Estados necesitados de la Eurozona, bajo condiciones estrictas y con la posibilidad de iniciar procedimientos de sanción contra aquéllos que vulnerasen las condiciones previstas. Este nuevo mecanismo de estabilidad debería sumir, además, las funciones que hoy desempeñan el Mecanismo Europeo de Estabilización Financiera (MEEF / EFSM), y el Fondo Europeo de Estabilidad Financiera (FEEF / EFSF), creados en mayo de 2010 y que deben desaparecer en junio de 2013.

La reforma del Art. 136 del TFUE necesita ser ratificada por la totalidad de los Estados miembros, para que el MEDE pueda entrar en funcionamiento, y este proceso de ratificación, en realidad, no se ha completado aún. En el momento de redactar estas líneas, sólo 13 Estados han ratificado la reforma del Art. 136. En este sentido, es curioso observar como España, uno de los Estados más interesados en que el MEDE entre en funcionamiento, ha tardado más de un año en proceder a la ratificación de esta reforma. ${ }^{33}$

En desarrollo de la reforma del Art. 136 del TFUE, los Estados miembros de la Eurozona concluyeron en Bruselas, el 11 de junio de 2011, un tratado internacional —al margen de los Tratados de la UE_- por el que se establece el Mecanismo Europeo de Estabilidad (MEDE), y en el que se regula en detalle su composición, funcionamiento y funciones. ${ }^{34}$ Sin embargo, cuando aún no se había completado siquiera su proceso de ratificación, el Tratado MEDE fue sustituido por un segundo Tratado MEDE, firmado también en Bruselas por los Estados de la Eurozona, el 2 de febrero de $2012 .{ }^{35} \mathrm{La}$ intención de la reforma del Tratado MEDE, apenas siete meses después de su alumbramiento, fue introducir en el mismo las decisiones adoptadas por los Jefes de Estado y de Gobierno de la Eurozona del 21 de julio y del 9 de diciembre de 2011, ante la persistencia de la crisis financiera. El objetivo fue, por un lado incrementar la flexibilidad del MEDE, a fin de hacerlo más eficaz, pero acentuando al mismo tiempo la condicionalidad en la prestación de las ayudas, y, por otro lado, adaptarlo ya al nuevo Tratado cuya elaboración fue decidida en la reunión del 9 de diciembre de 2011 —el Tratado de Estabilidad, Coordinación y Gobernanza en la Unión Económica y Monetaria (TECG)—-, de tal manera que las ayudas del MEDE quedasen vinculadas a la ratificación de este nuevo Tratado.

32 Consejo Europeo de 24 y 25 de marzo de 2011, Conclusiones (EUCO 10/11, Bruselas, 25 de marzo de 2011); Decisión del Consejo Europeo de 25 de marzo de 2011, que modifica el artículo 136 del Tratado de Funcionamiento de la Unión Europea en relación con un mecanismo de estabilidad para los Estados miembros cuya moneda es el euro (2011/199/UE) (DO L 91, 6.4.2011).

33 España procedió al depósito del instrumento de ratificación de la reforma del Art. 136 el 15 de junio de 2012 .

34 Treaty Establishing the European Stability Mechanism (ESM). Esta primera versión del Tratado no fue hecha pública en castellano. (Vid. este Tratado en:

http://consilium.europa.eu/media/1216793/esm\%20treaty\%20en.pdf

35 Tratado Constitutivo del Mecanismo Europeo de Estabilidad (MEDE). (Vid. este Tratado en:

http://www.european-council.europa.eu/media/582869/01-tesm2.es12.pdf 
El MEDE es, en realidad, una entidad financiera privada, con plena personalidad jurídica, perteneciente a los Estados miembros de la Eurozona — que son sus accionistas-, que tiene su sede y oficina principal en Luxemburgo. Su objetivo es la salvaguarda de la estabilidad financiera de la Eurozona en su conjunto, y la de sus Estados miembros en particular. Para ello, el MEDE puede prestar ayuda a los Estados miembros de la zona euro a través de varios instrumentos financieros, sometiendo la prestación de esta ayuda a una estricta condicionalidad, la cual varía también en función del instrumento de asistencia financiera elegido. Así, el MEDE puede prestar asistencia financiera precautoria (Art. 14), conceder préstamos a un Estado miembro (Art. 16), conceder préstamos dedicados específicamente a la recapitalización de las entidades financieras de un Estado miembro (Art. 15), adquirir títulos de deuda soberana emitidos por un Estado miembro en el mercado primario (Art. 17), o, en fin, realizar de operaciones en el mercado secundario en relación con los títulos de deuda soberana de un Estado miembro del MEDE (Art. 18). Y la condicionalidad a la que se somete la ayuda prestada puede adoptar diversas formas, desde la imposición de un programa de ajuste macroeconómico definido al efecto, hasta el control del cumplimiento continuo de las exigencias de estabilidad financiera y presupuestaria previstas, y de las condiciones establecidas para la concesión de la ayuda.

A estos efectos, el volumen máximo inicial de préstamo del MEDE se ha fijado en 500.000 millones de euros. Todos los Estados miembros de la Eurozona son miembros de pleno derecho del MEDE y, por lo tanto, destinatarios potenciales de sus ayudas, al mismo tiempo que participan en la designación de sus órganos gestores y en su financiación. ${ }^{36}$ En este último aspecto, el Tratado establece que el MEDE cooperará muy estrechamente con el Fondo Monetario Internacional, buscando su participación activa, tanto en los aspectos técnicos como financieros. Así, se espera que los Estados miembros de la zona del euro que soliciten la asistencia financiera del MEDE, dirijan también una petición similar al FMI. Y, en fin, en esta misma línea, el Tratado establece que los préstamos del MEDE gozan de la condición de acreedor preferente de manera similar a los del FMI, si bien se establece igualmente que la condición de acreedor del FMI prevalece sobre la del MEDE.

Finalmente, cabe decir que, si bien en su primera versión (11.7.2011), el Tratado MEDE fue elaborado antes de que lo fuese el Tratado de Estabilidad, Coordinación y Gobernanza en la Unión Económica y Monetaria (TECG), su segunda versión (2.2.2012) fue aprobada cuando el borrador final de éste último había sido ya aprobado por los Estados de la Eurozona - y asociados- , con motivo de la reunión del Consejo Europeo informal de 30 de enero de 2012; y lo fue, precisamente — como hemos visto en líneas anteriores-, para adaptar las previsiones del Tratado MEDE al nuevo TECG. En este sentido, caber decir que estos dos tratados son complementarios e inciden en una misma concepción y línea de actuación en el ámbito de la política económica y monetaria de la UE: a) Asegurar una más estrecha coordinación de las políticas económicas de los Estados, un equilibrio financiero y presupuestario, y un mutuo control de todo ello, a través del nue-

36 La participación española supone el 11,90\% del capital. España ha suscrito 833.259 acciones, por un valor de 83.325.900.000 de euros. 
vo TECG; y b) asegurar una asistencia financiera a los Estados miembros de la zona euro, en caso de necesidad, para poder corregir los desequilibrios existentes y atender a sus necesidades de liquidez, a través del MEDE.

De aquí, pues, que se establezca que, a partir del 1 de marzo de 2013, la concesión de toda asistencia financiera a través de los mecanismos previstos en el Tratado MEDE, estará condicionada a la previa ratificación del TECG por el Estado de que se trate. ${ }^{37}$ En todo caso — tal y como establece el Art. 2 del Tratado MEDE_, la adhesión al MEDE está abierta a los otros Estados miembros de la UE, a partir de la entrada en vigor de la decisión del Consejo por la que se suprima la excepción relativa a la adopción del euro a la que se refiere el Art. 140.2 del TFUE.

El Tratado MEDE entrará en vigor en la fecha en la que haya sido ratificado por un grupo de Estados signatarios cuyas cuotas iniciales de suscripción representen globalmente, como mínimo, el 90\% del total de suscripciones del capital autorizado (Art. 48 Tratado MEDE). En todo caso, la intención de los Jefes de Estado y de Gobierno de la zona euro es que este Tratado entre en vigor en julio de 2012. ${ }^{38}$ El Tratado MEDE, pues, se encuentra en vía de ratificación por los Estados signatarios, en el momento de redactar estas líneas.

\section{iii) «The Six Pack»}

La supervisión de la actividad presupuestaria de los Estados miembros por parte de la UE fue aún acentuada y complementada en noviembre de 2011 por un conjunto de seis normas jurídicas. Se trata del conjunto normativo conocido como el «paquete de seis» ( The Six Pack»), formado por cinco reglamentos y una directiva. ${ }^{39}$ En resumen, estas seis normas jurídicas, diferentes en su contenido, a pesar de su aparente similitud y de la materia común de la que se ocupan, establecen lo siguiente:

- Se introduce un sistema de sanciones para potenciar el cumplimiento de los componentes preventivo y corrector del Pacto de Estabilidad y Crecimiento en la zona del euro; para castigar la manipulación de las estadísticas macroeconómicas (la cuantía de la multa puede llegar al 0,2\% del PIB del Estado miembro

37 Preámbulo (5) del Tratado constitutivo del Mecanismo Europeo de Estabilidad; Preámbulo del Tratado de estabilidad, coordinación y gobernanza en la Unión Económica y Monetaria.

38 Declaración de los Jefes de Estado y de Gobierno de la zona del euro, Bruselas, 9 de diciembre de 2011, punto 13. La previsión inicial, cuando se formuló la primera versión del Tratado MEDE, era que éste entrase en vigor en julio de 2013.

39 «The Six Pack» está formado por: Reglamento (UE) n 1173/2011 del Parlamento Europeo y del Consejo, de 16.11.2011, sobre la ejecución efectiva de la supervisión presupuestaria en la zona del euro; Reglamento (UE) n ${ }^{\circ} 1174 / 2011$ del Parlamento Europeo y del Consejo, de 16.11.2011, relativo a las medidas de ejecución destinadas a corregir los desequilibrios macroeconómicos excesivos en la zona del euro; Reglamento (UE) $\mathrm{n}^{\circ} 1175 / 2011$ del Parlamento Europeo y del Consejo, de 16.11.2011, por el que se modifica el Reglamento (CE) $n^{\circ} 1466 / 97$ del Consejo, relativo al refuerzo de la supervisión de las situaciones presupuestarias y a la supervisión y coordinación de las políticas económicas; Reglamento (UE) nº 1176/2011 del Parlamento Europeo y del Consejo, de 16.11.2011, relativo a la prevención y corrección de los desequilibrios macroeconómicos; Reglamento (UE) $\mathrm{n}^{\circ}$ 1177/2011 del Consejo, de 8.11.2011, por el que se modifica el Reglamento (CE) $\mathrm{n}^{\circ}$ 1467/97, relativo a la aceleración y clarificación del procedimiento de déficit excesivo; y Directiva 2011/85/UE del Consejo, de 8.11.2011, sobre los requisitos aplicables a los marcos presupuestarios de los Estados miembros 
interesado); y para la corrección efectiva de los desequilibrios macroeconómicos excesivos en la zona del euro, cuando no se han tomado las medidas correctoras recomendadas por el Consejo. ${ }^{40}$

- Se establecen las normas que regulan el contenido, la presentación, el examen y el seguimiento de los Programas de Estabilidad y de los Programas de Convergencia. ${ }^{41}$

- Se define el contenido del Semestre Europeo para la coordinación de las políticas económicas de los Estados. ${ }^{42}$

- Se establece que los Estados velarán por la independencia profesional de las autoridades nacionales de estadística. ${ }^{43}$

- Se establece un mecanismo de alerta con objeto de facilitar la detección rápida y el seguimiento de los desequilibrios económicos y presupuestarios. ${ }^{44}$

- Se establecen disposiciones para acelerar y clarificar el procedimiento de déficit excesivo. ${ }^{45}$

- Se considerará excepcional y no sancionable un déficit público superior al valor de referencia (Art. 126.2.a TFUE), cuando obedezca a una circunstancia inusual sobre la cual no tenga ningún control el Estado. ${ }^{46}$

- Si se rebasa el valor de referencia de deuda pública, se considerará que ésta disminuye de manera suficiente y se aproxima a un ritmo satisfactorio al valor de referencia (Art. 126.2.b TFUE), en caso de que la diferencia con respecto al valor de referencia haya disminuido en los tres años anteriores a un ritmo medio de una veinteava parte al año. ${ }^{47}$

- Se establecen normas detalladas sobre las características que deben presentar los marcos presupuestarios de los Estados miembros. En este sentido, los Estados velarán por que la planificación presupuestaria se base en previsiones macroeconómicas y presupuestarias realistas, en un escenario probable o prudente. ${ }^{48}$

- Se establece que los Estados definirán un marco presupuestario a medio plazo creíble y efectivo, que incluya un horizonte de planificación presupuestaria de tres años como mínimo. ${ }^{49}$

- Se establecen que los Estados garantizarán que todas las medidas adoptadas abarquen de manera exhaustiva y coherente todos los subsectores de las administraciones públicas. ${ }^{50}$

40 Reglamento (UE) $n^{\circ} 1173 / 2011$; Reglamento (UE) n ${ }^{\circ} 1174 / 2011$.

41 Reglamento (UE) $\mathrm{n}^{\circ} 1175 / 2011$.

42 Reglamento (UE) n ${ }^{\circ} 1175 / 2011$.

43 Reglamento (UE) $\mathrm{n}^{\circ} 1175 / 2011$.

44 Reglamento (UE) $\mathrm{n}^{\circ} 1176 / 2011$.

45 Reglamento (UE) no $1177 / 2011$.

46 Reglamento (UE) n ${ }^{\circ} 1177 / 2011$.

47 Reglamento (UE) $\mathrm{n}^{\circ} 1177 / 2011$.

48 Directiva 2011/85/EU.

49 Directiva 2011/85/EU.

50 Directiva 2011/85/EU. 
iv) «The Two Pack»

En esta misma línea, se encuentra en fase de debate un nuevo paquete de dos medidas propuesto por la Comisión en noviembre de 2011 ( «The Two Pack»), el cual pretende, por un lado, obligar a los Estados del euro a presentar cada año sus proyectos de presupuestos respetando los mismos plazos, permitiendo además a la Comisión pronunciarse al respecto y, en su caso, pedir a los Gobiernos que los modifiquen; ${ }^{51}$ y, por otro lado, permitir un más estrecho seguimiento de los Estados de la eurozona que reciban ayuda financiera, o se encuentren en situación de grave inestabilidad financiera. ${ }^{52}$

\section{v) El Tratado de Estabilidad, Coordinación y Gobernanza en la Unión Económica y Monetaria}

El proceso que lleva a la formulación del TECG se desarrolla a lo largo del año 2011, cuando se hizo evidente que los instrumentos diseñados por la UE y los Estados miembros de la zona euro para estabilizar la situación y salir de la crisis financiera eran insuficientes para lograr los objetivos buscados. Era necesario ir más allá y adoptar decisiones más drásticas. En esta línea, comenzó a hacerse un lugar común la necesidad de realizar una reforma profunda de los Tratados, cuando menos en todo los referente a la «gobernanza económica» de la Unión.

El primer paso sólido en esta dirección se dio con motivo de las reuniones del Consejo Europeo y de los Jefes de Estado y de Gobierno de la zona euro, de los días 23 y 26 de octubre de 2011, y se completaría más tarde, en las reuniones del 8 y 9 de diciembre de 2011. ${ }^{53}$ En esta primera etapa, los Jefes de Estado y de Gobierno de la UE y de la zona euro acordaron, no sólo profundizar en la aplicación estricta de los instrumentos estratégicos y jurídicos ya existentes y diseñados a este respecto (Pacto de Estabilidad y Crecimiento, Estrategia Europa 2020; Semestre Europeo; Pacto por el Euro Plus; paquete de seis actos legislativos sobre gobernanza económica; Acta del Mercado Único), sino que, desde el punto de vista institucional, acordaron también a) reforzar el papel instrumental, vigilante y controlador, de la Comisión Europea en este terreno, dando un papel más relevante a estos efectos al Comisario responsable de los asuntos económicos y monetarios; y b) institucionalizar la Cumbre del Euro (Jefes de Estado y de Gobierno de la zona euro), con un Presidente específico —el «Presidente de la Cumbre del Euro»—, que debería ser elegido por los Jefes de Estado o de Gobierno de la zona del euro al mismo tiempo que el Consejo Europeo eligiese a su Presidente, y también para el

51 Proposal for a Regulation of the European Parliament and of the Council on common provisions for monitoring and assessing draft budgetary plans and ensuring the correction of excessive deficit of the Member States in the euro area (Brussels, 23.11.2011, COM(2011) 821 final, 2011/0386 (COD).

52 Proposal for a Regulation of the European Parliament and of the Council, on the strengthening of economic and budgetary surveillance of Member States experiencing or threatened with serious difficulties with respect to their financial stability in the euro área (Brussels, 23.11.2011, COM(2011) 819 final, 2011/385 (COD).

53 El domingo 23 de octubre se reunió el Consejo Europeo. La reunión del día 26 estaba prevista inicialmente sólo para los Jefes de Estado o de Gobierno de la zona euro, pero, a solicitud de otros Estados - notablemente el Reino Unido_-, y dada la relevancia común de la materia a tratar, se invitó también a la reunión a los demás Estados de la UE, no pertenecientes a la eurozona. 
mismo período: 2 años y medio renovable sólo una vez. En este sentido, se acordó que, hasta que ese Presidente fuese elegido, este papel lo realizase el actual Presidente del Consejo Europeo, Herman Van Rompuy. ${ }^{54}$

El Consejo Europeo tomó nota de la intención de los Jefes de Estado o de Gobierno de la zona del euro de buscar un fortalecimiento de su convergencia económica y de mejorar la disciplina presupuestaria a través de modificaciones limitadas del Tratado de Funcionamiento de la UE y, en este sentido, se acordó que cualquier modificación de los Tratados debería ser decidida por los 27 Estados miembros. A este objeto, el Consejo Europeo decidió pedir un informe al Presidente del Consejo Europeo y, sobre el mismo, volver a tratar este asunto en su siguiente reunión, de diciembre de 2011. Sin embargo, conscientes de la gravedad de la crisis, de la insuficiencia de las reformas introducidas por el Tratado de Lisboa para poder resolverla, y conscientes también de las enormes dificultades existentes para llevar a cabo una reforma ordinaria de los Tratados a estos efectos — debido a los requisitos procedimentales y a la exigencia de la unanimidad-, tanto la Canciller alemana, Angela Merkel, como el Presidente de la República francesa, Nicolas Sarkozy, venían pronunciándose públicamente, en los últimos meses, a favor de la realización de una reforma profunda de los Tratados, sin excluir la posibilidad de la formulación de un tratado nuevo, de carácter internacional —intergubernamental—, concluido al margen de los procedimientos de la UE. ${ }^{55}$

Pocos días antes de la reunión del Consejo Europeo, y de la cumbre de los jefes de Estado o de Gobierno de la zona euro, del 8 y 9 de diciembre de 2011, se presentaron las dos únicas propuestas formales de reforma: la del Presidente del Consejo Europeo, Herman Van Rompuy, y la propuesta conjunta del Presidente de Francia, Nicolas Sarkozy, y la Canciller alemana, Angela Merkel. Similares en su contenido material, ambas propuestas, sin embargo, se diferenciaban en su visión sobre el procedimiento a seguir.

La decisión finalmente adoptada, el 9 de diciembre de 2011, tomó la forma de una Declaración conjunta de los Jefes de Estado y de Gobierno de la zona euro, ${ }^{56}$ al margen de las conclusiones oficiales del Consejo Europeo (las cuales, por otra parte y de manera sorprendente, apenas mencionaron esta cuestión, casi como si la transcendente decisión y el duro debate que la precedió, nunca hubieran tenido lugar). ${ }^{57} \mathrm{La}$ decisión de acudir finalmente a la redacción de un tratado al margen de los Tratados de la Unión, propuesta por Merkel y Sarkozy, en vez de reformar estos últimos, vino, en realidad, favorecida por el veto del Reino Unido, que se opuso vigorosamente a cualquier intento de reforma de los Tratados de la UE, a través de los procedimientos formalmente previstos, que implicase introducir en los mismos el contenido material que se había incluido en las

54 Consejo Europeo de 23 de octubre de 2011, Conclusiones (EUCO 52/11, CO EUR 17, CONCL 5) (Bruselas, 23 de octubre de 2011); Declaración de los Jefes de Estado o de Gobierno de la UE, Bruselas, 26 de octubre de 2011.

55 Véase, por ejemplo, la rueda de prensa siguiente a la reunión de Merkel y Sarkozy en Berlín, el 9 de octubre de 2011, en la que anunciaron que Francia y Alemania propondrían «modifications importantes aux traités européens», en la línea de lograr una "plus grande intégration de la zone euro [...] pour éviter des dérapages budgétaires.»

56 Consejo Europeo, Declaración de los Jefes de Estado y de Gobierno de la Zona del Euro (Bruselas, 9 de diciembre de 2011).

57 Consejo Europeo, Conclusiones del Consejo Europeo de 9 de diciembre de 2011 (EUCO 139/11, CO EUR 24, CONCL 6) (Bruselas, 9 de diciembre de 2011). 
propuestas presentadas. De manera principal, el Reino Unido no quería que la regulación interna de su mercado financiero se viese afectada por las previsiones restrictivas que en su entender - la reforma llevaba consigo.

La Declaración conjunta de los Jefes de Estado y de Gobierno de la zona euro, del 9 de diciembre de 2011, es, en realidad, un primer borrador que diseña ya, en toda su extensión, el contenido material de lo que luego será el Tratado de Estabilidad, Coordinación y Gobernanza en la Unión Económica y Monetaria (TECG), que comenzará a ser redactado a los pocos días.

Así, el primer borrador del TECG, elaborado por los servicios jurídicos del Consejo, fue presentado a los Estados miembros por el Presidente del Consejo Europeo, Van Rompuy apenas una semana después, el 16 de diciembre de 2011. A partir de aquí, el debate y la formulación jurídica del TECG fueron trasladados a un organismo creado al efecto: una versión ampliada del Grupo de Trabajo de Eurogrupo, con un total de unas cien personas, en representación de los Estados miembros de la zona euro, de la Comisión y del Parlamento Europeo, presidida por Georges Heinrich (Director del Tesoro, del Ministerio de Finanzas de Luxemburgo y Vicepresidente del Eurogrupo).$^{58}$ Además del primer borrador, elaborado por el servicio jurídico del Consejo, el Grupo de Trabajo llegó a elaborar cuatro borradores más, ${ }^{59}$ el último de los cuáles fue el que se presentó finalmente a los Jefes de Estado y de Gobierno de la zona euro y de los demás Estados comprometidos en el proceso, que dieron su aprobación al mismo, el 30 de enero de 2012, con motivo de la celebración en Bruselas del Consejo Europeo informal de esa fecha. El TECG sería firmado por veinticinco de los veintisiete Estados miembros de la UE en una reunión solemne que tuvo lugar en Bruselas, el 2 de marzo de 2012, con motivo de la celebración del Consejo Europeo del 1 y 2 de marzo. El nuevo Tratado, pues, tuvo finalmente el apoyo global de todos los Estados miembros de la UE - pertenecientes, o no, a la zona euro-, excepto el Reino Unido, que se opuso a la reforma desde el principio, y de la República Checa que se sumó a la oposición poco después.

El TECG es, pues, un tratado internacional, concluido por veinticinco Estados miembros de la UE, cuyo objetivo es — como establece su Art. 1— «reforzar el pilar económico de la unión económica y monetaria» mediante la adopción de un conjunto de normas destinadas, a) en primer lugar, a promover la disciplina presupuestaria a través de un pacto presupuestario; $b$ ) en segundo lugar, a reforzar la coordinación de sus políticas

58 Además de los representantes de los Estados miembros de la zona euro — 3 por Estado— se invitó también a participar en los debates a representantes de los demás Estados miembros de la UE, de la Comisión (representada por Luis Romero Requena, Director General del Servicio Jurídico, y Marco Buti, Director General de Asuntos Económicos y Financieros) y del Parlamento Europeo (representado por Elmar Brok, Partido Popular Europeo, Roberto Gualtieri, Alianza Progresista de Socialistas y Demócratas, y Guy Verhofstad, Alianza de los Demócratas y Liberales por Europa; Daniel Cohn-Ben, Partido Verde Europeo, fue nombrado sustituto). El Grupo del Trabajo del Eurogrupo (Eurogroup Working Group, EWG), es el órgano que prepara las reuniones de los Ministros de Finanzas de la zona euro —el Eurogrupo-. El Grupo celebró sus reuniones en el edificio Charlemagne de la Comisión.

59 El Grupo de Trabajo se reunió por primera vez en Bruselas, el 20 de diciembre de 2011. A partir de aquí, los diferentes borradores del TECG fueron concluidos y presentados a los Estados el 5, el 10, y el 19 de enero de 2012. Los Ministros de Economía y Finanzas (Ecofin) analizaron el texto en su reunión del 23 y 24 de enero y, finalmente, la quinta y última versión es la que se presentó a los Jefes de Estado y de Gobierno, para su aprobación, el 30 de enero de 2012. 
económicas; y c) en tercer lugar, a mejorar la gobernanza de la zona del euro. En última instancia, se entiende que ello es la base imprescindible sobre la que poder conseguir los objetivos de la Unión Europea en materia de crecimiento sostenible, empleo, competitividad y cohesión social.

a) En lo que se refiere, en primer lugar, a la disciplina presupuestaria, cabe decir que ésta es la parte a la que el TECG dedica un mayor espacio y atención (Arts. 3-8). Ello es un buen indicador de cuál es la preocupación principal del legislador en el momento de redactar el Tratado, sobre todo, si tenemos en cuenta que - como hemos visto ya - una buena parte de las previsiones establecidas en este terreno provienen de normativa ya establecida y en pleno vigor en el Derecho de la UE. Se trata, en fin, de reforzar mecanismos jurídicos ya existentes, más que de establecer un conjunto normativo enteramente nuevo.

Así, en primer lugar, con respecto al déficit público (Art. 3), el TECG propone un pacto por el cual los Estados firmantes, yendo mucho más allá de las previsiones del Art. 126 del TFUE y el Protocolo $\left(\mathrm{n}^{\circ} 12\right)$ sobre el procedimiento aplicable en caso de déficit excesivo, que lo desarrolla, se comprometen a mantener una situación presupuestaria de sus administraciones públicas de equilibrio o de superávit. Se entiende, sin embargo, que los Estados que sobrepasen ese límite están respetando esta norma si logran un ajuste estructural anual del $0,5 \%$ del PIB en su objetivo nacional específico de reforma a medio plazo (Art. 3.1.b). Se admite que ese límite alcance el 1\% del PIB, cuando la deuda pública esté muy por debajo del $60 \%$ del PIB y los riesgos para la sostenibilidad a largo plazo de las finanzas públicas sean bajos. Y se admite igualmente que los Estados puedan desviarse temporalmente de su respectivo objetivo a medio plazo en caso de que se produzcan circunstancias excepcionales. ${ }^{60}$

Los Estados garantizarán la rápida convergencia hacia su respectivo objetivo a medio plazo (Art. 3.1.b). El calendario para lograr dicha convergencia lo propondrá la Comisión. Los avances hacia el objetivo a medio plazo serán objeto de una evaluación global en consonancia con el Pacto de Estabilidad y Crecimiento revisado.

Por otra parte, la exigencia jurídica de equilibrio o de superávit presupuestario debe ser incorporada al Derecho nacional de los Estados mediante disposiciones permanentes que tengan fuerza vinculante — «preferentemente de rango constitucional»— y sean de obligado cumplimiento en los procedimientos presupuestarios (se da un plazo de un año para hacer la reforma normativa correspondiente). El Estado incumplidor de esta obligación puede ser llevado ante el Tribunal de Justicia de la UE y ser objeto de sanción pecuniaria, de acuerdo con el Art. 260 TFUE (Art. 3.2).

Se establece un mecanismo corrector que se activará de manera automática en el caso de que se observen desviaciones significativas del objetivo a medio plazo, o de la senda de ajuste hacia dicho objetivo, por parte de los Estados. Si el mecanismo se activase, el Estado en cuestión estará obligado a aplicar las medidas que se le indiquen y en el plazo especificado, para corregir las desviaciones (Art. 3.1.e). Si un Estado se niega a cumplir con

60 El propio Tratado se encarga de definir que entiende por circunstancias excepcionales: acontecimientos inusuales fuera del control del Estado afectado y que tengan una gran incidencia en su situación financiera, o períodos de grave recesión económica, siempre que la desviación temporal del objetivo no ponga en peligro la sostenibilidad presupuestaria a medio plazo (Art. 3.3.b). 
las recomendaciones, puede ser denunciado ante el Tribunal de Justicia por otro Estado, autónomamente, o a instancias de la Comisión. Si el Estado incumplidor se niega a ejecutar la decisión del TJ, puede ser denunciado de nuevo ante el TJ por otro Estado, autónomamente, o a instancias de la Comisión. Finalmente, el TJ puede sancionar al Estado con una multa (que no puede exceder el $0,1 \%$ de su PIB).

En segundo lugar, con respecto a la deuda pública (Art. 4), se reitera la previsión general - para todos los Estados de la UE_ del Art. 126 del TFUE, desarrollado por el Protocolo ( $\left.\mathrm{n}^{\circ} 12\right)$ sobre el procedimiento aplicable en caso de déficit excesivo: la deuda pública será «significativamente» inferior al 60\% del PIB. Pero, de manera específica, para los Estados firmantes del TECG, se establece que los Estados que excedan ese límite de deuda están obligados a reducirla a un ritmo medio de una veinteava parte al año, según lo dispuesto en el Art. 2 del Reglamento (CE) no 1467/97 del Consejo, de 7.7.1997, relativo a la aceleración y clarificación del procedimiento de déficit excesivo, modificado por el Reglamento (UE) n 1177/2011 del Consejo, de 8.11.2011 (Art. 4). Además, los Estados deben comunicar al Consejo y a la Comisión sus planes de emisión de deuda pública, a fin de coordinarlos con los del resto de los Estados (Art. 6).

b) En lo que se refiere, en segundo lugar, al refuerzo de la coordinación de las políticas económicas, se establece el compromiso de utilizar el mecanismo de la «cooperación reforzada» para profundizar en la coordinación de las políticas económicas de los Estados miembros de la Eurozona (en los términos previstos en los Arts. 20 TUE y Arts. 326-334 TFUE), y el compromiso de que los proyectos de reforma en el ámbito de las políticas económicas serán consultados y coordinados ex-ante con los demás Estados de la Eurozona.

c) $\mathrm{Y}$ en lo que se refiere, en tercer lugar, a la mejora de la gobernanza de la zona del euro, el Tratado institucionaliza la Cumbre de la Zona Euro, con la presencia de los Jefes de Estado o de Gobierno de los Estados miembros. También podrán asistir a las reuniones el Presidente de la Comisión, el Presidente del BCE y el Presidente del Eurogrupo (Art. 12.1). El presidente del Parlamento Europeo puede ser invitado (Art. 12.5).

El Presidente de la Cumbre de la Zona Euro será elegido por los Jefes de Estado o de Gobierno de la Eurozona (por mayoría simple) al mismo tiempo que se elige al Presidente del Consejo Europeo (Art. 12.1).

La Cumbre de la Zona Euro se reunirá cuando sea necesario y, por lo menos, dos veces al año (Art. 12.2). Los Jefes de Estado o de Gobierno de los Estados signatarios del Tratado que no son miembros de la Eurozona podrán participar en las reuniones de la Cumbre de la Zona Euro una vez al año, por lo menos, para discutir asuntos relacionados con la ejecución del Tratado de Estabilidad, o siempre que se vaya a discutir asuntos relacionados con la competitividad de los Estados signatarios, la modificación de la arquitectura global de la Eurozonza, o las reglas fundamentales que se vaya a aplicar a la misma en el futuro (Art. 12.3).

Las reuniones de la Cumbre son preparadas por el Presidente de la Cumbre, en cooperación con el Presidente de la Comisión (Art. 12.4). El Eurogrupo asiste en la preparación de las reuniones de la Cumbre y seguirá el cumplimiento de sus acuerdos. El Presidente del Eurogrupo podrán asistir, a estos efectos, a las reuniones de la Cumbre. 
El Presidente de la Cumbre del Euro presentará un informe al PE después de cada reunión de la Cumbre (Art. 12.5) e informará a los demás Estados de la UE de las reuniones de la Cumbre y de sus acuerdos (Art. 12.6).

Los Parlamentos Nacionales de la Eurozona crearán, con el PE, una Conferencia permanente de representantes de las Comisiones parlamentarias nacionales correspondientes (Art. 13). Parece como si, con ello, se tratase de establecer una COSAC específica de la eurozona. ${ }^{61}$

d) El Tratado incluye también unas previsiones finales, en las que se establece que éste entrará en vigor el 1 de enero de 2013, siempre que, al menos, doce Estados firmantes de la Eurozona hayan depositado su instrumento de ratificación (Art. 14.2). Por otra parte, el Tratado se mantiene abierto a los otros Estados de la UE que quieran asociarse en el futuro (Art. 15). Y, dada su vocación de integración en el ordenamiento jurídico de la UE, a pesar de haber nacido al margen de ella, el Tratado prevé que sus previsiones serán incluidas en los Tratados de la UE (TUE y TFUE) en el plazo de 5 años (Art. 16).

\section{PACTO PARA EL CRECIMIENTO Y EL EMPLEO}

Finalmente, los intentos de reforma de la gobernanza económica de la UE encuentran en el mes de junio de 2012 un momento clave en la inflexión de la dinámica que se había venido siguiendo en los últimos años — desde 2010 — hasta entonces. Se trata de pasar ahora de una estricta política de austeridad, concentrada exclusivamente en la conquista del equilibrio presupuestario, a una política más flexible, que haga coincidir el equilibrio presupuestario con el crecimiento económico y del empleo.

La crisis económica y financiera, en cambio, no sólo se mantiene, sino que se acentúa, al menos en alguno de los Estados grandes de la Unión, como España e Italia, lo que la hace aún más preocupante para la eurozona y para el conjunto de la UE.

Así, la Cumbre de la Eurozona, de 28 junio 2012, hubo de adoptar transcendentales acuerdos que inciden en aspectos institucionales y materiales del gobierno de la UE. En esta línea, a) se acuerda la creación de un mecanismo único de supervisión bancaria (basado en Art. 127.6 TFUE); b) se acuerda atribuir al MEDE — cuando aún no se ha completado el proceso de ratificación de su Tratado — ${ }^{62}$ la posibilidad de recapitalizar directamente a los bancos, con una condicionalidad estricta, cambiando así su contenido sustancial, que hacía que sólo pudiese financiar directamente a los Estados miembros de la eurozona. c) El Fondo (o Facilidad) Europeo de Estabilidad Financiera (FEEF) y el MEDE serán utilizados «de manera flexible y eficiente con objeto de esta-

61 COSAC son la iniciales antiguas en francés (Conférence des Organes Parlementaires Spécialisés dans les Affaires Communautaires, hoy: de l'Union Européenne) de la conferencia que une a los representantes de las comisiones parlamentarias encargadas de los asuntos de la UE en los Parlamentos nacionales de los Estados miembros.

62 En el momento de redactar estas líneas, sólo 9 de los 17 Estados miembros de la eurozona han concluido la ratificación del Tratado MEDE, y España, uno de los países objetivamente más interesado en su ratificación sólo entregó el instrumento de ratificación del Tratado el 2 de julio de 2012, más de un año después de su primera redacción. 
bilizar los mercados», para beneficio de aquellos Estados miembros que respeten sus recomendaciones específicas. En este sentido, d) la ayuda que España solicitaba para refinanciar un sector de su banca, se acuerda que sea canalizada a través de la FEEF, hasta que esté disponible el MEDE, en 2013. Por otra parte, e) se establece que el BCE será el agente director de la FEEF y el MEDE para conducir sus operaciones de mercado. ${ }^{63}$

El Consejo Europeo del 28-29 de junio de 2012, que siguió inmediatamente a la Cumbre de la Eurozona aprobó el denominado «Pacto para el Crecimiento y el Empleo», que marca el cambio, siquiera sea tenue, en la política general de equilibrio y austeridad seguida por la UE hasta ese momento. ${ }^{64}$ Así, este Pacto propone, entre otras cosas además de proseguir el saneamiento presupuestario-, promover el crecimiento y la competitividad; hacer frente al desempleo y a las consecuencias sociales de la crisis; modernizar la administración pública, en particular haciendo frente a los retrasos del sistema judicial, reduciendo las cargas administrativas y desarrollando servicios de administración electrónica; profundizar en el mercado interior, eliminando las barreras restantes; lograr en 2015 un mercado único digital; reducir la carga reglamentaria global de la UE; impulsar la financiación de la economía mediante la movilización de 120.000 millones de euros (equivalentes al 1\% de la RNB de la UE); usar parte de de los Fondos Estructurales para compartir el riesgo de préstamo del BEI y facilitar garantías a los préstamos en materia de conocimiento, infraestructura estratégica y acceso a financiación para las PYME; y, en fin, acelerar el proceso de aprobación del paquete de dos medidas normativas ( "The Two Pack»), al que hemos hecho referencia en líneas anteriores.

\section{V. ¿HACIA UNA AUTÉNTICA UNIÓN ECONÓMICA Y MONETARIA?}

Finalmente, debe ser destacado aquí el hecho de que, en el Consejo Europeo de 2829 de junio de 2012, se presentó un relevante informe del Presidente del Consejo Europeo, Van Rompuy, titulado «Hacia una auténtica Unión Económica y Monetaria», ${ }^{65}$ del que los Jefes de Estado o de Gobierno dicen solamente tomar nota. Es evidente que las propuestas de Van Rompuy iban mucho más allá de lo que varios miembros del Consejo Europeo podían aceptar, por lo que se decidió dejar el tema en estudio y volver sobre él en otra reunión. En realidad, el Consejo Europeo invita a su Presidente a elaborar «una hoja de ruta pormenorizada y acotada en el tiempo para la consecución de una auténtica Unión Económica y Monetaria», y la atribución de nuevos poderes al BCE, a partir del Art. 127.6 del TFUE.

La propuesta de Van Rompuy pretende conseguir una nueva gobernanza de la UE basada en una plena integración de tres ejes: a) un nuevo marco financiero integrado, para asegurar la estabilidad financiera, en particular de la eurozona; $b$ ) un marco presupuestario integrado, para asegurar una política fiscal sólida en el ámbito estatal y en el

63 Euro Area Summit Statement, Brussels, 29 June 2012.

64 Consejo Europeo de 28 y 29 de junio de 2012, Conclusiones (EUCO 76/12, CO EUR 4, CONCL 2) (Bruselas, 29 de junio de 2012).

65 Towards a Genuine Economic and Monetary Union. Report by President of the European Council Herman Van Rompuy (EUCO 120/12, PRESSE 296, PR PCE 102) (Brussels, 26 June 2012).

UNED. Teoría y Realidad Constitucional, núm. 30, 2012, pp. 59-87. 
ámbito de la UE; c) y un marco integrado de política económica, para promover un crecimiento sostenible, empleo y competitividad; a lo que añade d) el refuerzo de la legitimidad y la responsabilidad democráticas de la Unión.

a) En lo que se refiere al nuevo marco financiero integrado, Van Rompuy propone en concreto la creación de una autoridad supervisora con poder sobre la totalidad de los bancos europeos; el establecimiento de una garantía de los depósitos; y un mencanismo europeo de resolución.

b) En lo que se refiere al marco presupuestario integrado, Van Rompuy propone el establecimiento de una sólida política fiscal en el nivel nacional y en el nivel europeo, basada en la coordinación, decisión conjunta, aplicación reforzada y la emisión de deuda pública común; caminar más decididamente hacia la unión fiscal; el acuerdo común sobre los límites a imponer en los equilibrios presupuestarios anuales y en la deuda pública de los Estados miembros; la emisión de deuda pública común; y el desarrollo en la zona euro de una autoridad fiscal común, a modo de Hacienda Pública Europea ( "Treasury office»).

c) En lo que se refiere al marco integrado de política económica, Van Rompuy, propone la plena utilización de los mecanismos existentes (Semestre Europeo, Pacto Euro Plus, etc.) para asegurar el desarrollo de la políticas de la Unión y para promover un crecimiento sostenible, empleo, competitividad y un funcionamiento adecuado de la Unión Económica y Monetaria. Y, en esta línea, basado muy seguramente en las insuficiencias manifestadas por varios Estados miembros tras las últimas ampliaciones y, desde luego el caso lamentable de Grecia —aunque ello no se explicite en su informe-, Van Rompuy propone también la adopción de medidas políticas y administrativas para desarrollar las capacidades de las «instituciones nacionales».

d) En lo que se refiere al refuerzo de la legitimidad y la responsabilidad democráticas de la Unión, Van Rompuy se limita a proponer una implicación más estrecha del Parlamento Europeo y de los Parlamentos Nacionales.

$* * *$

TITLE: The constitutional Reform and the economic Governance in the European Union

ABSTRACT: This article analyzes the reforms adopted by the EU and its Member States addressed at introducing and consolidating in their respective legal systems the basic principle of financial or budgetary balance, commonly known as the "golden rule "; that is to say, the requirement by which the whole of the public administration, at its different levels of government, must keep on a regular basis a situation of balanced budget or with surplus. In this line, this article analyzes firstly the precedents of this legal requirement in comparative constitutional law and then the amendments made by

Germany, Spain and Italy on their constitutional texts, but also the frustrated constitutional reform initiated in France. And secondly, this article analyzes the reforms made in the economic governance of the EU by means of both politicalstrategic documents - which establish the general framework and the basic governing principles - and legal provisions which develop and implement them. In this respect, this article analyzes political-strategic documents such as the Stability and Growth Pact, Europe 2020, the Euro Plus Pact; and the legal provisions of Art. 126 of the TFEU and the excessive deficit procedure; the amendment of Art. 136 of the TFEU and the European Stability Mechanism; the set of six legal instruments commonly known as "The Six Pack ": and the new reinforcing set of two legal instruments - still under discussion - commonly known as "The Two Pack ". Finally, this article analyzes also the Treaty on Stability, Coordination and Governance in the Economic and Monetary Un ion, agreed outside the framework of the EU legal system, and the recent proposals adopted by European Council of June 28- 29, 2012, concerning a new "Compact for Growth and Jobs" and the President of the European Council report "Towards a Genuine Economic and Monetary Union ",

RESUMEN: Este artículo analiza las medidas de reforma adoptadas en el marco de la UE y de sus Estados miembros a efectos de introducir y consolidar en sus respectivos ordenamientos jurídicos el principio básico de estabilidad financiera o 
presupuestaria, conocido comúnmente como la "regla de oro "; es decir, la exigencia de que toda la administración pública, en sus diferentes niveles de gobierno, mantenga de manera permanente una situación presupuestaria de equilibrio o de superávit. Así, primer lugar, se analizan los precedentes en el Derecho constitucional comparado de esta exigencia constitucional y luego las reformas de los textos constitucionales realizadas en Alemania, España e Italia, pero también la frustrada reforma constitucional iniciada en Francia. y, en segundo lugar, se analizan las reformas en la gobernanza económica de la UE, realizadas tanto a través de documentos político-estratégicos, que establecen el marco general y los principios básicos de actuación, como a través de textos jurídicos que los desarrollan y aplican en la práctica. Así, el artículo analiza en detalle documentos político-estratégicos como el Pacto de Estabilidad y Crecimiento, Europa 2020, el Semestre Europeo, el Pacto por el Euro Plus; y las previsiones jurídicas del Art. 126 del TFUE y el procedimiento aplicable en caso de déficit excesivo; la reforma del Art. 136 del TFUE y el Mecanismo Europeo de Estabilidad; el paquete de seis medidas jurídicas conocido como "The Six Pack"; y la propuesta de nuevas medidas jurídicas de refuerzo en este terreno conocido como "The Two Pack". El artículo, finalmente, analiza también el Tratado de Estabilidad, Coordinación y Gobernanza en la Unión Económica y Monetaria, concluido al margen del ordenamiento jurídico de la UE, y las más recientes propuestas del Consejo Europeo de 28-29 de junio de 2012, sobre un nuevo "Pacto por el Crecimiento y el Empleo" y el informe del Presidente del Consejo Europeo titulado "Hacia una auténtica Unión Económica y Monetaria".

KeY WorDs: Balanced budget; Compact for Growth and Jobs; Economic and Monetary Union; economic governance; Euro Plus Pact; Europe 2020; European Semester; European Stability Mechanism; European Union; financial stability; "golden rule ", Stability and Growth Pact; "The Six Pack ": "The Two Pack ": Treaty on Stability, Coordination and Governance in the Economic and Monetary Union

Palabras Clave: Estabilidad financiera; estabilidad presupuestaria; Europa 2020; gobernanza económica; Mecanismo Europeo de Estabilidad; Pacto de Estabilidad y Crecimiento; Pacto por el Crecimiento y el Empleo; Pacto por el Euro Plus > regla de oro; Semestre Europeo; "The Six Pack"; "The Two Pack"; Tratado de Estabilidad, Coordinación y Gobernanza en la Unión Económica y Monetaria; Unión Económica y Monetaria; Unión Europea

FECHA DE RECEPCIÓN: 16.06.2012

FECHA DE ACEPTACIÓN: 19.07.2012 